\title{
UMA REFLEXÃo Sobre A AÇÃo SOCIAL EM WEBER E GEERTZ
}

\author{
Juliana Gonzaga Jayme
}

RESUMO: Nesse artigo procuro refletir, do ponto de vista da ação social, os aspectos que aproximam e os que distanciam a sociologia compreensiva de Max Weber e a Antropologia Interpretativa de Clifford Geertz.

\section{APRESENTAÇÃO}

O presente artigo tem como objetivo uma reflexão sobre alguns aspectos da obra de Max Weber e Clifford Geertz, especialmente aqueles que dizem respeito à idéia de ação, tal como ela é formulada em sua teoria: sua relação com a subjetividade, o problema dos valores em relação ao sentido da ação e, por fim, uma consideração a respeito da compreensão/interpretação no que se refere ao ator e ao pesquisador.

A opção por trabalhar com esses dois autores foi motivada por diferentes aspectos: em primeiro lugar, me interessa uma reflexão mais cuidadosa a respeito da idéia de ação social, talvez o principal objeto de investigação da "sociologia compreensiva" de Weber, retomado exaustivamente por Geertz em sua "antropologia interpretativa". 
Em segundo lugar, porque Geertz tem como uma de suas "fontes inspiradoras", exatamente a sociologia weberiana. O antropólogo propõe um conceito semiótico de cultura, vista como "teia de significados", estando o homem amarrado a essas teias que ele próprio teceu. A "antropologia interpretativa" - da qual Geertz é visto como um dos "pais" busca compreender os significados "rebatidos" nessas teias, os "fluxos de comportamento", as ações simbólicas dos indivíduos ou grupos de indivíduos, justamente o que dá sentido aos símbolos. Tal conceito de cultura é assumidamente apoiado na teoria weberiana, sendo a própria noção de ação simbólica influenciada pela concepção de Weber de ação social.

Sendo assim, apesar de vários aspectos distintos entre a discussão de Weber e Geertz - que naturalmente serão tratados no ensaio - há uma questão de extrema importância que se refere ao método e que vale a pena, no meu entender, se tornar objeto de reflexão. Tanto um quanto outro (e repito, Geertz apoiado em Weber), têm a pretensão metodológica de "entrar no mundo" motivacional do outto, buscando o sentido da ação - a compreensão/interpretação.

Com o intuito de organizar a exposição, dividi preliminarmente o texto. No primeiro momento me dedico ao tratamento de Weber à questão, para depois introduzir Geertz. Termino então com a busca da relação entre os dois, no tópico aqui chamado "Considerações Finais".

\section{1 - MAX WEBER}

\section{1 - CONTEXTUALIZANDO O AUTOR}

Antes de iniciar a discussão propriamente dita - referente à ação social em Weber - me parece interessante, ainda que brevemente, situar histórica e espacialmente o autor, uma vez que, acredito, o contexto no qual ele se insere se revela como fundamental para o seu pensamento. As 
"fontes inspiradoras", o momento político e principalmente intelectual de meados do século XIX, no qual as ciências histórico-sociais estão sendo debatidas, em especial, no que diz respeito à validade de seus procedimentos de investigação.

Como sabemos, o positivismo se firmava como corrente dominante no século XIX, entretanto seu domínio não era absoluto, na medida em que provocou reações, notadamente na Alemanha, o país que mais interessa neste caso. Na realidade, a Alemanha do século XIX aparece como um local onde a polêmica em torno das ciências históricosociais - seus procedimentos metodológicos - se dá de forma contundente.

Dilthey é um filósofo emblemático desse momento, talvez um dos mais importantes representantes do anti-positivismo. A partir de uma síntese entre a história e a psicologia, o autor critica o positivismo de Comte, principalmente no que diz respeito ao método de investigação das "ciências do espírito". Para Dilthey, estas devem elaborar métodos que sejam objetivos, mas específicos, diferentes daqueles utilizados para as ciências da natureza, uma vez que os fenômenos investigados pelas ciências humanas são significantes para aqueles que os vivem e os investigam. O cientista pertence ao mundo observado por ele, desta forma, antes de procurar explicá-lo, ele deve compreendê-lo. E a compreensão leva em conta a linguagem, o diálogo, a pluralidade dos significados e o contexto histórico. Ou seja, em contraposição a uma razão científica - preocupação básica do positivismo - Dilthey aponta para a riqueza de uma razão histórica para a compreensão dos fenômenos sociais, a qual leva em conta a subjetividade, o indivíduo e o contexto histórico, pois o fundamental para a compreensão é a recuperação do sentido, situado no tempo e relacionado a uma visão de mundo e a um ponto de vista. A experiência histórica é vista por Dilthey como sendo uma realidade múltipla. 
"O ponto de partida das ciências do espirito será (...) a experiência vivida que o bomem tem de seu mundo; e seu procedimento fundamental (...) a expressão na qual este se objetiva bistoricamente e a 'compreensão' que tem de tal objetivação remetendo-la à sua origem. Estas disciplinas empregam categorias que constituem a tradução a termos abstratos das formas estruturais da vida - categorias como as de valor, significado, fim - elas criam métodos particulares para remontar desde cada manifestação bistoricamente determinada até o espirito dos bomens que a produziram, no qual consiste o procedimento da compreensão, análogo ao da introspeç̧ão." (Rossi: 1973, pp.13-14)

Segundo Dilthey, as ciências naturais, diferentemente, estariam preocupadas com a explicação, com a construção de um sistema de leis, viável a partir do estabelecimento de relações causais. Para um cientista natural é possível pensar desta forma, até porque, o mundo que ele investiga é reconhecido como sendo distinto dele próprio, mesmo que ele esteja em relação constante com este mundo. Além disso, esse mundo se torna apreensível e inteligível, a partir da utilização de outros instrumentos de investigação.

"O que distingue as ciências do espirito das ciências da natureza no terreno metodológico é a antitese entre explicação e compreensão, entre a causalidade e 0 'compreender.'”(Rossi: op.cit., p.14).

Naturalmente, Dilthey não estava sozinho nesse debate e foi também muito criticado. Windelband e Rickert, por exemplo, procuravam também mostrar a validade das ciências do espírito, mas de maneira distinta daquela utilizada por Dilthey. Para os primeiros, a "relação de valor" seria a questão fundamental para o objeto histórico e é neste ponto que está a validade das ciências da cultura e sua diferença com relação às ciências da natureza. Como coloca Rossi: 
"A natureza é a realidade considerada com referência ao geral; a bistória, a realidade considerada com referência ao individual. Mas considerar um objeto como individual significa determiná-lo em forma de individuo, fundado sobre uma 'relação de valor' com certos critérios que tem permitido isolá-lo e caracterizá-lo. O mundo bistórico se apresenta, em consequência, como uma multiplicidade organizada de individuos, pertencentes a uma totalidade e inseridos em um processo de desenvolvimento; sua base está constituida pela referência da realidade empírica do mundo dos valores, que o qualifica como o mundo da 'cultura'." (op.cit., p.15)

Weber constrói sua "sociologia compreensiva" nesse ambiente e suas "fontes inspiradoras" de alguma forma estão aí. Naturalmente, não são apenas os autores citados aqui que influenciaram Weber. Marx e Nietzsche, por exemplo, tiveram grande impacto sobre sua obra. Mas a "hermenêutica" de Dilthey e as afirmações de Rickert e Windelband se tornaram "material de interlocução" para as preocupações weberianas. Se as posições de Rickert e Wimdelband estão mais de acordo com o pensamento de Weber, as idéias de Dilthey não são descartadas totalmente; antes, são interpretadas pelo sociólogo alemão e relacionadas às de Rickert.

\section{2- UM ESBOÇO SOBRE A IDÉIA DE AÇÃO SOCIAL}

Neste tópico, pretendo tratar da ação social - na realidade o interesse aqui é mais uma descrição - em Weber, mas pensando apenas em alguns aspectos desse conceito, já que seria impossível e pretensioso abarcá-lo em sua totalidade.

O conceito de ação social é fundamental para a "sociologia compreensiva" de Weber, na medida em que, para o autor, o objetivo desta ciência está associado exatamente ao entendimento - via interpretação - 
da ação social. Tal conceito é definido por Weber como sendo uma conduta humana, dotada de significaşão e que se orienta pela ação de outros. ${ }^{1}$

'Deve-se entender por sociologia (...): uma ciência que pretende entender, interpretando-a, a ação social para, desta maneira, explicá-la causalmente em seu desenvolvimento e efeitos. Por 'afão' deve-se entender uma conduta bumana (que pode consistir num ato externo ou interno; numa condição ou numa permissão) sempre que o sujeito ou os sujeitos da ação envolvam-na de um sentido subjetivo. A 'ação social', portanto, é uma ação em que o sentido indicado por seu sujeito, ou sujeitos, refere-se à conduta de outros, orientando-se por esta em seu desenvolvimento." (Weber: 1969, p.05)

A citação acima é, do meu ponto de vista, emblemática para mostrar a "força" da idéia de ação social para a sociologia weberiana. Em algumas linhas, o autor delineia o que entende por sociologia, qual o seu objeto de investigação e como este objeto deve ser estudado. Parece-me que aqui ele torna clara sua postura epistemológica que - diferentemente de um estruturalismo marxista ou durkheimiano - é interpretativa. O sujeito é retomado em Weber, pois para ele os indivíduos atribuem significados subjetivos às ações e, mais ainda, às estruturas, orientando dessa forma sua conduta. $\mathrm{O}$ observador, então, não teria que se preocupar com as estruturas, mas com o significado atribuído a elas pelos indivíduos. Assim, a subjetividade, colocada entre parêntesis por Marx e Durkheim, torna-se objeto de investigação em Weber. Para ele a socio-

${ }^{1}$ É fundamental, para que a ação seja social, que ela se oriente em função da ação de outro. Ou seja, não é qualquer ação humana que tem o caráter social. Para se tornar social, a ação precisa estar imbuída de uma relação significativa. " $A$ colisão involuntária entre dois ciclistas nada tem de uma relafãa social; no entanto, esta aparece quando os dois tentam evitar um ao outro ou, após o choque, quando comecam as invectivas de parte a parte ou se inicia uma troca de palavras para um entendimento amigável." (Freund, 1970, pp. 80, 81) 
logia tem como ponto de partida a ação individual e não a sociedade ou a estrutura social. Não existe, em seu esquema de análise, uma realidade objetiva já dada. É exatamente a realidade individual que compõe e dá sentido à sociedade, à realidade social. Como afirma Gabriel Cohn:

“... o objeto de análise sociológica não pode ser definido como a sociedade ou grupo social, ou mediante qualquer outro conceito com referência coletiva. No entanto, é claro que a Sociologia trata de fenômenos coletivos, cuja existência não ocorreria a Weber negar. O que ele sustenta é que o ponto de partida da análise sociológica só pode ser dado pela ação de individuos e que ela é 'individualista' quanto ao método. Isso é inteiramente coerente com a posição sempre sustentada por ele, de que nos fenômenos sociais não se pode presumir a existência já dada de estruturas sociais dotadas de um sentido intrínseco; vale dizer, em termos sociológicos, de um sentido independente daqueles que os individuos imprimem às suas ações." (1991, p. 26)

Outro aspecto que chama atenção e se apresenta como fundamental em sua análise é a questão do sentido envolvido pelo sujeito na ação. A ação é social exatamente porque é carregada de sentido impresso pelo sujeito que a está realizando. Cabe ao observador entender este sentido para que a ação se torne inteligível. Vale a pena destacar aqui que, para Weber, o sentido que importa captar na sociologia é aquele "subjetivamente visado" pelos agentes em uma ação concreta. Não interessa o sentido "exato", ou "justo", ou "verdadeiro", tal qual interessa para disciplinas de caráter dogmático, como a metafísica.

'Por 'sentido' entendemos o sentido subjetivo indicado pelos sujeitos da ação, seja a) existente de fato: num caso bistoricamente dado; como média e como aproximação numa determinada massa de casos: ou b) construido num tipo ideal, com atores desse caráter. Não se trata, de forma alguma, de um sentido 'objetivamente justo' ou de um sentido 
'verdadeiro', fundado metafisicamente. Aqui, precisamente, é que se enraiza a diferença entre as ciências empiricas da ação (a sociologia, a bistória) face a todas as ciências dogmáticas (jurisprudência, lógica, ética, estética), as quais pretendem investigar em seus objetos o sentido 'justo'e 'válido' ". (Weber: 1969, p.06)

Entretanto, por maior que seja a importância que Weber dê à idéia de sentido para a interpretação da ação social, segundo alguns autores, ele não chega a uma definição formal desta noção em seu trabalho e, nesse ponto, seu raciocínio é visto de certa forma, como sendo nebuloso. Gabriel Cohn, por exemplo, é categórico ao afirmar que Weber não explica o que entende por sentido. Em suas palavras:

“... é preciso ver o que Weber entende por 'sentido'. E nesse ponto ele não ajuda muito, pelo menos nas suas formulações iniciais sobre 0 tema. É que ele está mais preocupado com enfatizar que o sentido a que ele se refere é aquele subjetivamente visado pelo agente (...) do que com definir o conceito. Interessa, enfim, aquele sentido que se manifesta em ações concretas e que envolve um motivo sustentado pelo agente como fundamento da sua ação. Mas em nenbum ponto se encontrará uma definição de 'sentido', como aliás também ocorre com o conceito de 'compreensão'. Nesse ponto o raciocinio de Weber parece circular: sentido é o que se compreende e compreensão é captação de sentido". (Op.cit., p.27)

Mesmo criticando duramente esta questão no trabalho de Weber, Cohn (op.cit.) sugere que o conceito de motivo pode auxiliar, funcionando como uma ponte entre o sentido (ação) e a compreensão (objetivo), uma vez que o sentido manifestado nas ações concretas envolve um motivo, o qual fundamenta a ação do agente. Dessa forma, para compreender a ação é necessário ao sociólogo reconstruir o motivo que causa esta ação. 
“... quando se fala de sentido na sua acep̧ão mais importante para a análise, não se está cogitando da gênese da ação mas sim daquilo para o que aponta, para o objetivo visado nela; para o seu fim, em suma". (Cohn: op.cit., p.27)

Apesar de toda a crítica, enfim, o próprio Cohn (op.cit) nos dá pistas para entender a noção de sentido no pensamento de Weber. A ação social seria, na concepção weberiana, um processo - o sentido está intrinsecamente ligado à maneira como se dá o encadeamento deste processo - no qual (em um modelo típico-ideal) haveria uma seqüência definida de elos significativos. Tais elementos se articulam no que é denominado por Weber "cadeia motivacional", na qual há uma seqüência de atos parciais, cada um operando como fundamento do seguinte e, apesar disso, a ação social possui uma unidade. $\mathrm{E}$ a unidade da ação acaba por se tornar reveladora no que se refere à possibilidade de compreender 0 que Weber entende por sentido, pois "o sentido é responsável pela unidade dos processos e é através desta que os torna compreensíveis. Ou seja: é somente através do sentido que podemos apreender os nexos entre os diversos elos significativos de um processo particular de ą̧ão e reconstruir esse processo como uma unidade que não se desfaz numa poeira de atos isolados. Realizar isso é precisamente compreender o sentido da af̧ão". (Cohn: op.cit., p.28)

Vale aqui uma nota sobre a noção de relação social. Seria uma conduta de vários agentes reciprocamente orientada e dotada de conteúdos significativos. Aqui a idéia de probabilidade é essencial, na medida em que não há como ter certeza de que se agirá socialmente de uma maneira específica.

"A relação social consiste só e exclusivamente - ainda que trate de formações sociais como 'estado', 'igreja', 'corporação', 'matrimônio' etc. - na probabilidade de que uma forma determinada de conduta social, 
de caráter recíproco por seu sentido, tenha existido, exista ou possa existir'. (Weber: 1969, p.22) ${ }^{2}$

Depois do que foi dito sobre a ação social e sua explicação, que se faz a partir de conexões de sentido, é possível entender mais facilmente a idéia de compreensão em Weber.

Partindo de alguns autores, entre os quais Dilthey e Rickert, Weber formula sua concepção de compreensão ${ }^{3}$, a qual está ligada à interpretação e à causalidade e tem como objetivo captar o sentido da ação social. A compreensão não estaria, de maneira alguma, vinculada à intuição, na medida em que ela só se torna possível a partir da conexão de sentido da ação, reconstruída pelo observador. Ou seja, reconstruindo o encadeamento significativo que se dá na ação social, o investigador é mais capaz de "compreender". Além disso, a compreensão não é um processo psicológico, na medida em que a idéia não é compreender o indivíduo, mas o sentido da ação realizada por ele. Segundo Freund (op.cit.), inclusive, Weber critica Simmel por tratar a compreensão como sendo um processo essencialmente psíquico. Daí torna-se mais clara ainda a importância do indivíduo para uma investigação sociológica, pois, ao conferir sentido à ação, o indivíduo a torna social e, portanto, objeto de investigação da sociologia.

Um outro aspecto imprescindível para entender a sociologia compreensiva se refere à causalidade. Para Weber, a compreensão tem necessariamente que estar aliada à imputação causal, pois é esta que garante à

${ }^{2}$ Não cabe aqui tratar mais profundamente dessa questão, mas uma das proposições fundamentais da sociologia compreensiva de Weber é a natureza probablística das estruturas sociais.

${ }^{3}$ Como já foi dito, Weber não foi um diltheano, entretanto, buscou elementos da hermenêutica para formular sua idéia de compreensão. No último tópico - considerações finais - esta questão será melhor tratada, especialmente na relação entre Weber e Geertz. 
pesquisa compreensiva o caráter científico e, mais importante, a possibilidade de estabelecer regras gerais.

"A combinagão entre a explicasãa e a compreensão dá por sua vez um sentido à imputagão causal: torna-se causalidade significativa, o que vale dizer que as relaģöes causais se tornam por isso mesmo relaģões significativas". (Freund: op.cit., p.79)

Neste ponto, pode-se perceber que Weber, ao mesmo tempo em que foi influenciado pelas formulações historicistas do século XIX - por exemplo a hermenêutica de Dilthey - propôs uma sociologia que, por outro lado, se diferencia dessas formulações, na medida em que combina explicação causal e compreensão ${ }^{4}$. Para ele, acontecimentos históricos e objetos culturais deveriam ser compreendidos tanto do ponto de vista interpretativo (hermenêutico) - buscando o sentido da ação - como do ponto de vista explicativo (explicação causal). Como aponta Hall:

"As condições objetivas causadoras de um acontecimento ou de uma objetivaşão cultural tinham que ser rigorosamente construidas, por assim dizer, de fora, demonstrando sempre que possivel como a cadeia causal produzia o 'resultado' sob análise naquela forma particular, $e$ não um outro qualquer. Mas essa mesma via teria também que ser seguida 'de dentro' - em termos da lógica de seus significados. Explicafões histórico-causais, argumentava Weber, também tinham que ser 'adequadas a nivel de significąãão'”. (Hall: 1980, p.23)

${ }^{4}$ Dilthey, diferentemente de Weber, trata a compreensão e a explicação como sendo dois métodos além de autônomos, opostos e, para esse autor, porque a experiência histórica e a cultura são realidades múltiplas, diversificadas, cabe ao observador interpretá-las, compreendê-las em sua particularidade - como em Weber - mas não em busca de regularidades. A explicação caberia às ciências naturais, estas sim, preocupadas com o estabelecimento de leis e com as relações causais.

Temáticas, Campinas, 6(11/12):195-221, jan./dez. 1998 
Este ponto merece ser melhor discutido. Para Weber, o conceito de cultura, ele próprio, é um conceito de valor. "A realidade empirica é 'cultura' para nós porque e na medida em que a relacionamos com idéias de valor'. Ela abrange aqueles e somente aqueles componentes da realidade que através desta relą̧ão tornam-se significativos para nós". (Weber: 1992, p.127) Assim, não é a cultura, em sua totalidade, que possui significado para os indivíduos, mas apenas uma parte (e pequena) da realidade. Por outro lado, é exatamente o sentido conferido à ação pelo sujeito - sentido que está intrinsecamente vinculado às idéias de valor - que interessa à análise da cultura $\mathrm{e}$ esse sentido não tem como ser geral. Segundo Weber, então, só é possível analisar uma parcela finita - aquela significativa - dos diferentes fenômenos sociais. Ou seja, a análise da cultura tem que partir dos fenômenos singulares e daqueles que possuem uma significação geral para a cultura, pois só eles podem ser explicados de forma causal e, mais importante, é preciso procurar conexões causais concretas - que possuem significado - pois é apenas desta maneira que se pode alcançar leis gerais.

\begin{abstract}
“... todo conbecimento da realidade cultural é sempre um conbecimento subordinado a pontos de vista especificamente particulares. Quando exigimos do bistoriador ou do sociólogo a premissa de saber distinguir entre o essencial e o secundário, de possuir para esse fim os pontos de vista necessários, queremos unicamente dizer que ele deverá saber consciente ou inconscientemente - os elementos da realidade a 'valores culturais' universais, e destacar aquelas conexões que, para nós, se revestem de significado". (Weber: op.cit., p.131).
\end{abstract}

Enfim, a ciência não está livre de valores. Os valores dominantes em uma dada sociedade, por exemplo, vão influenciar a concepção cien-

${ }^{5}$ Aqui a influência de Rickert torna-se clara. Esse autor aponta para a relação de valor como sendo a questão essencial das ciências da cultura, pois o mundo da cultura seria o mundo dos valores. 
tífica. Mesmo a idéia de tipo-ideal é orientada por valores, pois são estes que definem o objeto de investigação do sociólogo, o sentido da ação. A partir daí torna-se claro que, em Weber, a objetividade do conhecimento não estaria desligada de valores, antes, dependeria dos valores partilhados, legítimos (no sentido de reconhecidos e aceitos) no interior de uma dada sociedade.

\section{2 - CLIFFORD GEERTZ}

\section{1 - BREVES LINHAS SOBRE SUAS INFLUÊNCIAS E SEU LUGAR NA TEORIA ANTROPOLÓGICA}

Assim como Weber, Clifford Geertz tem como uma das suas fontes inspiradoras a teoria alemã da cultura e, sobretudo, a hermenêutica. Entretanto, também como Weber repudia a "empatia" proposta por Dilthey - o fato de se sentir como o outro. Para Geertz, não somos nativos, portanto não nos sentimos como eles. Antes, a etnografia pretende interpretar as ações simbólicas dos agentes, buscando entrar no mundo motivacional deles, ou seja, o que ele busca na hermenêutica é, como Weber, a compreensão de uma ação, que só poderia ser feita em uma ciência da cultura, a partir do sentido.

Além da teoria alemã da cultura, Geertz se inspira numa fenomenologia herdada de $S c h u t z^{6}$ e, pode-se dizer, é a partir daí que ele irá se opor à "empatia" de Dilthey. Para Geertz é necessário justapor os esquemas de referência do nativo a esquemas de referência do cientista - o

${ }^{6}$ Hall (1980) afirma que a preocupação de Schutz com a interpretação intersubjetiva, o significado como sendo conseqüência de uma reciprocidade de subjetividades, vem de Weber. 
diálogo entre o êmico e o ético ${ }^{7}$. Para o autor, importa o desenvolvimento de um método que possa descrever e analisar a estrutura significativa da experiência da forma como ela é apreendida pelos membros de uma sociedade determinada e em um contexto "histórico-espacial" particular. "... em suma, uma fenomenologia científica da cultura". (Geertz: 1989a, p.229)

Weber também, como já foi apontado, é uma referência marcante em Geertz. Em "A interpretação das Culturas", uma coletânea de artigos, na qual a preocupação central seria, grosso modo, uma definição do conceito de cultura, Geertz assume claramente a influência da sociologia compreensiva de Weber.

'O conceito de cultura que eu defendo (...) é necessariamente semiótico. Acreditando, como Max Weber, que o bomem é um animal amarrado a teias de significados que ele mesmo teceu, assumo a cultura como sendo essas teias e a sua análise, portanto, não como uma ciência experimental em busca de leis, mas como uma experiência interpretativa, à procura do significado". (Geertz: op.cit, p.15)

Para pensar Geertz dentro da teoria antropológica, vale a pena remeter à matriz disciplinar ${ }^{8}$ sugerida por Cardoso de Oliveira (1988) em um artigo sobre a história da antropologia. Partindo das categorias de ordem e (des)ordem, o autor diferencia "Antropologia Interpretativa" e "Antropologia Tradicional", esta última sustentada pelos paradigmas da

${ }^{7}$ A diferença entre o êmico e o ético foi bastante trabalhada pela Escola de Chicago. $\mathrm{O}$ êmico estaria vinculado à lógica intrínseca ao ator social (o ponto de vista do nativo); o ético seria a conclusão generalizante, a lógica racionalmente entendida como um padrão universalizante.

${ }^{8} \mathrm{~A}$ matriz disciplinar seria exatamente a articulação sistemática de um conjunto de paradigmas, de maneira tal que eles possam coexistir no tempo, mantendo-se simultaneamente ativos e eficientes.

${ }^{9}$ A Antropologia Interpretativa teria Geertz, como já foi dito, como um de seus fundadores. A "Antropologia Tradicional" (chamada assim pelos interpretativistas) con- 
ordem, enquanto a antropologia interpretativa inauguraria a perspectiva da (des)ordem.

Os paradigmas da ordem sustentariam as "escolas" das primeiras décadas desse século e estariam explicitados nos discursos de cada uma delas, especialmente no que se refere à "domesticação" de alguns elementos conceituais, quais sejam, o indivíduo, a história e a subjetividade. Mas é necessário, na concepção de Cardoso de Oliveira, reiterar que se trata realmente de uma domesticação de tais elementos e não de uma exclusão, propriamente dita. Como afirma o próprio autor (op.cit.: p.19):

'No máximo se trataria de uma exclusão metódica quando, na bipótese de uma difficil domesticajão, os elementos seriam submetidos a uma certa epoché, isto é, seriam postos entre colchetes, neutralizados. Mas sua existência latente ou manifesta no âmbito da disciplina (...) seria facilmente aferivel pelo exercicio de sua negasão: negar a proeminência da subjetividade, do individuo ou da bistória é ter esses elementos ao menos sob controle".

A “ Antropologia Interpretativa" seria a instauradora da perspectiva da (des)ordem, na medida em que reformula a maneira de tratar de tais elementos. Baseada no paradigma hermenêutico, propõe a intersubjetividade (forma socializada de subjetividade), o que seria uma maneira de assumir a subjetividade, mas de algum modo abrindo caminho para que esta seja analisada e criticada. Este caminho para críticas, que distancia o subjetivismo da postura intersubjetiva, pode se dar através da explicitação conceitual que implica em um certo rigor na exposição dos

formaria três "escolas" do pensamento antropológico, vindas de tradições distintas e que atualizam três paradigmas quais sejam, a racionalista (Escola Francesa), funcionalista (Escola Inglesa e culturalista (Escola Americana).

Temáticas, Campinas, 6(11/12):195-221, jan./dez. 1998 
procedimentos e do arcabouço teórico-metodológico, bem como torna possível uma certa vulnerabilidade, já que não "se esconde" no rótulo de ciência objetiva.

A intersubjetividade compreende a importância do "horizonte cultural" do sujeito estudado e sua interseção com o "horizonte do pesquisador" no momento do fazer etnográfico. Esse é o espaço de interação do repertório do cientista social com as representações privilegiadas no cotidiano do pesquisado.

"A fusão de horizontes implica que na penetração do borizonte do. outro não abdicamos de nosso próprio borizonte. Assumimos nossos preconceitos". (Cardoso de Oliveira: op.cit., p.21)

Neste sentido, o paradigma hermenêutico escapa da coerção da objetividade proposta pelas outras "escolas". A história passa a ser vista como historicidade : uma história vivida, não linear, não exterior aos indivíduos. $\mathrm{O}$ indivíduo é visto a partir de sua forma personalizada, o indivíduo cultural, socializado, que assume sua individualidade. A ênfase no indivíduo escapa, porém, de um dito "psicologismo", na medida em que este não é encarado como fim último de análise, lugar da cultura. Mas, tanto o nativo quanto o pesquisador aparecem aqui como individualidades reconhecidas.

Esta abordagem interpretativa na Antropologia nasceu, pode-se dizer, nos Estados Unidos da década de 60, sendo Geertz um de seus principais expoentes nessa época. Hoje em dia poderíamos dizer que existem várias correntes que derivam (na maior parte das vezes questionando) da antropologia interpretativa de Geertz, possuindo o rótulo de "Antropologia Pós-Moderna". ${ }^{10}$ Entretanto, os diferentes autores do

${ }^{10}$ É necessário ressaltar aqui que o que é chamado de antropologia pós-moderna são, na realidade várias correntes - como já foi dito - $\mathrm{e}$, mais importante, a partir da 
que foi chamado de "corrente pós-moderna da antropologia" tratam a cultura das mais diversas maneiras e, talvez não seja demais dizer, "radicais"11. O que faz com que eles sejam colocados em um mesmo "rótulo" - formando uma "escola" - é, em primeiro lugar, a crítica à tradição da disciplina; em seguida a importância que os diferentes autores dão à interpretação e, mais importante, a idéia de se pensar a cultura como texto e a observação como sendo uma fusão de horizontes, os do antropólogo e os do nativo: o "encontro etnográfico". ${ }^{12}$

O antropólogo tenta ler os textos que estão em jogo e não alguma coisa que seja exterior e que, por dedução, explicaria os significados do jogo. A preocupação é com o sentido e as interpretações, antes de explicar os eventos, compreendê-los. Assim, o meta-discurso científico é colo-

grande influência de autores franceses - entre os quais Derrida, Foucault, Baudrillard, Lyotard e, mesmo Bourdieu - o que os antropólogos americanos fizeram foi uma crítica e um questionamento não só à chamada "antropologia tradicional", mas também à antropologia interpretativa de Geertz. Em uma palavra, seria um processo de transformação desta antropologia interpretativa.

${ }^{11}$ Tyler, por exemplo, poderia ser visto como um desses antropólogos com um discurso radical a respeito da própria antropologia. Para ele, o pensamento científico seria um "modo arcaico de consciência" (citado em Cardoso de Oliveira: op.cit., p.31) e a etnografia não seria "representação" nem "metáfora", não seria "alegoria" nem tampouco "descrição". Resta saber o que ela seria além de um "modo arcaico de consciência”.

12 Uma reflexão sobre o "encontro etnográfico" pode ser encontrada em Crapanzano: 1985. O autor faz um trabalho, visto por muitos como radical, mas que trata exatamente dessas questões. Inicia o seu texto dizendo que o livro é um experimento. Afirma ainda que não pretende fazer uma nova antropologia, antes, o que ele quer é chamar atenção para o encontro etnográfico e mostrar como ele interfere no texto antropológico. Pois, segundo Crapanzano, os antropólogos tendem a proclamar sua neutralidade e, mais do que isso, invisibilidade no trabalho de campo e, portanto, no texto final. Assim, acabam por eliminar a si próprios do encontro etnográfico o que, para Crapanzano, é uma negociação de subjetividades, produzindo uma "figura estática" dos povos estudados. 
cado sob suspeita e, mais ainda, o próprio autor é questionado frente ao saber do nativo.

“As interpretą̧ões geradas nesse 'encontro etnográfico' (...) obedecem a dinâmica daquilo que os hermeneutas chamam de fusão de horizontes. E o texto que se procura elaborar como resultante final desse confronto (termo quem sabe melhor do que encontro) não pode estar mais submetido a um autor todo soberano, único intérprete de seus dados; mas deve integrar de alguma maneira o saber do Outro e, se possivel, serpolifonico, onde as vozes dos Outros tenham a chance de serem ouvidas." (Cardoso de Oliveira: op.cit., p.33)

\section{2- GEERTZ: A IDÉIA DE CULTURA E A AÇÃo SOCIAL}

Para pensar o conceito de ação social em Geertz, é necessário remeter ao seu conceito de cultura, essencialmente semiótico, como ele próprio diz. A análise de cultura desse autor pressupõe a ação simbólica do indivíduo, visto como agente cultural, cujas ações dão sentido a um emaranhado de símbolos que é a cultura. Para compreender a cultura é necessário entender o sentido da ação dos indivíduos e isso só é possível a partir de uma "descrição densa"13. Segundo Geertz, toda ação é carregada de significação. $O$ antropólogo, então, para fazer uma descrição densa - em oposição a uma descrição superficial - não deve descrever o que está materialmente expresso, mas a teia de significados, que está por trás do comportamento efetivo e seu sentido, ou seja, a ação simbólica.

'Fazer a etnografia é como tentar ler (no sentido de 'construir uma leitura de') um manuscrito estranho, desbotado, cheio de elipses, incoe-

${ }^{13}$ Essa noção de "descrição densa" é retomada de Gilbert Ryle. 
rências, emendas suspeitas e comentários tendenciosos, escrito não com os sinais convencionais do som, mas com exemplos transitórios do comportamento modelado". (Geertz: 1989a, p.20)

Ao definir seu conceito de cultura, Geertz parte de negações. Primeiramente ele aponta para o que a cultura não é para, em seguida, dizer o que ela seria. A cultura não é um comportamento padronizado, não é um sistema fechado e nem tampouco um conjunto de idéias que orientariam a ação dos indivíduos na sociedade. Também não é uma realidade super-orgânica, como sugeriu Kroeber. Pensar a cultura a partir dessas noções seria reificá-la ou reduzi-la.

A cultura seria "um documento de atuação" e, mais importante, seria pública. E é pública porque o significado, impresso nas ações dos indivíduos, o é. Segundo Geertz, o próprio pensamento é público, social. Tal afirmação poderia parecer paradoxal em um primeiro momento, mas o que fica claro aqui é que, para o autor, o indivíduo é essencial para a compreensão da cultura, está sempre presente na investigação. É, como em Weber, o agente. Mas, por outro lado, não é instância última de análise. É o indivíduo socializado que pensa, que pratica e interpreta ações simbólicas, produzindo significados. $O$ indivíduo, então, antes de ser domesticado ou colocado entre parêntesis, é investigado no que o autor chama de seus "fluxos de comportamento".

No sentido de entender a cultura, então, Geertz trabalha com as ações cotidianas dos indivíduos. São estes que pensam, entretanto esse pensamento se torna público na medida em que é “... um tráfico de símbolos significantes - objetos em experiência (rituais e ferramentas; idolos esculpidos e buracos de água; gestos, marcaşões, imagens e sons) sobre os quais os homens imprimiram significado...”. (Geertz: op.cit., p.227), sendo o significado também públi$\mathrm{co}$, exatamente porque é socialmente reconhecido ${ }^{14}$.

${ }^{14}$ A noção te símbolos significantes de Geertz diz respeito não a uma significação 
Geertz aponta para a dificuldade de se entender a cultura a partir das idéias de homens comuns na sua vida cotidiana, ou seja, sugere que não é fácil para o estudo da cultura, a definição do seu objeto. Entretanto, nos dá pistas neste sentido, exatamente quando afirma que o ato de pensar é público, é uma ação social que se dá “... no mesmo público em que ocorrem outros atos sociais..."(Geertz: op.cit., p.227). Ao perceber o pensamento como uma troca do que ele chama de símbolos significantes, demonstra que os significados incorporados aos símbolos são passíveis de serem interpretados a partir de uma investigação empírica.

'É por intermédio dos padrões culturais, amontoados ordenados de simbolos significativos, que o homem encontra sentido nos acontecimentos através dos quais ele vive. $O$ estudo da cultura, a totalidade acumulada de tais padrões, é, portanto, o estudo da maquinaria que os individuos e grupos de individuos empregam para orientar a si mesmos num mundo que de outra forma seria obscuro". (Geertz: op. cit, p.228)

O autor aponta também para a escolha dos padrões culturais a serem eleitos pelo antropólogo para uma investigação e coloca que cabe ao sujeito pesquisador interpretar quais os padrões são os mais importantes para os sujeitos pesquisados. $O$ antropólogo tem que reconstruir a lógica informal da vida social que é real. Não se trata de observar idéias, mas ações sociais. É necessário partir do comportamento real, da experiência. Para o autor, não é o estabelecimento de regularidades abstratas o que importa, mas justamente o fluxo de comportamento dos indivíduos, suas ações e o sentido disso tudo. A coerência não é uma característica da cultura, por esta razão, um sistema social não é qualificado a partir da coerência dos seus códigos.

virtual, reificada, mas ao fato de que tais símbolos são atualizados dentro de um contexto que compreende seus usos nas ações simbólicas. 
'Deve atentar-se para o comportamento, e com exatidão, pois é através do fluxo de comportamento - ou, mais precisamente, da ação social - que as formas culturais encontram articulação". (Geertz: op.cit., p.27)

A etnografia, então, é interpretativa e o que ela interpreta é o fluxo da ação social, da vida social. É importante, para Geertz, que se priorize um momento deste fluxo e o relato deste momento é feito sob dimensões microscópicas, mas com possibilidade de se entender uma questão mais geral. Assim, é válido trabalhar com os problemas universais (como a noção de pessoa, o tempo, o poder, por exemplo), mas em um contexto determinado, pois, para ele, o desenvolvimento da ciência se dá exatamente a partir de soluções particulares ocorridas em contextos particulares. As grandes abstrações só podem ser feitas a partir de fatos singulares. Por esta razão, a etnografia, na concepção interpretativa de Geertz, é microscópica. A cultura é um contexto, assim, sua compreensão também deve ser contextualizada, levando em conta a ação simbólica de sujeitos também contextualizados.

"Como sistemas entrelaçados de signos interpretáveis (o que eu chamaria de simbolos, ignorando as utilizações provinciais), a cultura não é um poder, algo ao qual podem ser atribuidos casualmente os acontecimentos sociais, os comportamentos, as instituições ou os processos; ela é um contexto, algo dentro do qual eles podem ser descritos com densidade". (Geertz: op.cit., p.24)

A partir daí se torna ainda mais clara a idéia de Geertz de que a cultura só pode ser compreendida a partir de comportamentos de indivíduos que poderiam soar como banais, mas que na realidade é o que os torna acessíveis ao olhar do observador. É necessário “ver as coisas do ponto de vista do nativo" (Geertz: 1983, p.58). A compreensão (desde os 
hermeneutas, passando por Weber) não pode ser alcançada através da repetição da vivência do "outro", mas da relação entre o pesquisador e o sujeito estudado (a fusão de horizontes). É importante valorizar o que é dito pelo "outro", dialogar com o nativo. A linguagem é o meio onde se dá a experiência hermenêutica e, como já foi apontado, Geertz herda algumas das postulações desta corrente filosófica. Interpretar, então, diz respeito à manutenção de um diálogo com o nativo. É preciso conversat com ele, sem ignorar seu ponto de vista. Isto, por sua vez, não se confunde com uma tentativa de tornar-se nativo, mas interpretá-lo em suas ações.

'Nada mais necessário para compreender o que é a interpretação antropológica, e em que grau ela é uma interpretação, do que a compreensão exata do que ela se propõe dizer - ou não se propõe - de que nossas formulações dos sistemas simbólicos de outros povos devem ser orientados pelos atos" (Geerz: 1989a, pp.24-25)

Ou seja, as descrições de determinada cultura são construções e, mais ainda, são construções feitas pelos antropólogos e não pelos nativos daquela cultura. A etnografia, então, e os próprios textos antropológicos são interpretações de interpretações, porque interpretam o que foi interpretado em primeira mão pelos nativos daquela cultura e, portanto, são ficções, no sentido de que são construídos, “... o sentido original de fictio - não que sejam falsas, não-factuais ou apenas experimentos de pensamento". (Geertz: op.cit., p.26)

Enfim, pode-se dizer que, para Geertz, a descrição densa é o principal instrumento para se chegar à interpretação, na medida em que ela possibilita que se alcance o significado das ações sociais, que a dimensão simbólica da ação seja "traduzida" através do sentido que o autor lhe confere. Além disso, a antropologia interpretativa permite que o significado de uma ação social seja inscrito no universo da humanidade, como 
sendo real, vivido e experimentado por determinado grupo em determinado contexto.

\section{3- CONSIDERAÇÕES FINAIS:}

\section{BREVES LINHAS NA BUSCA DA ARTICULAÇÃo ENTRE WEBER E GEERTZ}

Parece que ficou claro, durante a exposição, que a "antropologia interpretativa" de Geertz e a "sociologia compreensiva" de Weber possuem alguns aspectos que as aproximam. A começar pela idéia de compreensão, da captação do sentido da ação a partir do ponto de vista do sujeito, o agente. Tanto em Weber, como em Geertz, o indivíduo se torna objeto de investigação sociológica, exatamente por ser ele o ator que atribui sentido à sua ação. A análise sociológica, então, só pode ser alcançada através do sentido destas ação.

Entretanto, existem alguns pontos que distanciam o pensamento desses autores, por exemplo, o que diz respeito à relação entre explicação e compreensão e quanto ao estabelecimento de leis gerais - a garantia do "status" de ciência para uma pesquisa compreensiva, na concepção de Weber. Assim, para ele, compreensão e explicação causal se articulam. A sociologia buscaria entender a ação social a partir da compreensão de seu sentido, mas a partir daí, procuraria explicá-la causalmente. Em Geertz, diferentemente - e aqui ele se aproxima mais da hermenêutica - a explicação não interessa, e não é possível, para uma análise da cultura. Não é necessário estabelecer leis a priori. O que interessa é compreender o "fluxo de comportamento" dos indivíduos, suas ações cotidianas e particulares. A partir daí pode-se chegar aos grandes temas. A etnografia possui um caráter microscópico. Mais do que isso, ao discutir sobre a relação entre as 
idéias de Weber e Geertz, Azzan (1993) afirma que para um e outro a ação social é a base do sentido, entretanto, em Weber a ação é ela própria racional e por isso produz sentido, diferentemente de Geertz:

\begin{abstract}
"Ao contrário de Weber, e talvez ai esteja uma real originalidade do pensamento de Geertz, é o sentido que proporciona um entendimento sobre o mundo, e a racionalidade é apenas uma expressão desse entendimento. $A$ racionalidade, também ela, está mesmo inserida dentro de um ponto de vista. Assim, só há racionalidade se houver sentido. A racionalidade, segundo os pressupostos de Geertz, também é uma racionalidade para." (Azzan: op. cit., pp. 16-17)
\end{abstract}

Por outro lado, a idéia de uma interpretação microscópica em Geertz, vem de Weber. Este último afirma que a realidade é finita e, portanto, cabe ao observador selecionar uma parcela desta realidade - exatamente aquela que possui significado, orientada por valores, para os indivíduos - como objeto de investigação. Esta seleção parte da ação individual, mas acaba por ser construída heuristicamente, a partir do tipoideal, que seria um instrumento válido para o cientista se orientar nessa infinitude que é o real. É a partir do tipo-ideal que o sociólogo pode encontrar o sentido da ação racional. A compreensão, então, é uma construção, os conceitos sociológicos são construções.

Para Geertz, as interpretações também são construídas - ficções mas ele não se utiliza de um modelo típico-ideal para fazer a etnografia, pois, diferentemente de Weber, ele não está buscando regularidades - a cultura é um emaranhado de símbolos articulados pelos indivíduos. Assim, o que interessa a Geertz é o comportamento real dos indivíduos, sua experiência, a partir daí é possível compreender uma cultura, mas, reitero - uma cultura específica. $\mathrm{O}$ texto antropológico, então, seria ao mesmo tempo um relato científico e uma ficção. É um ensaio relativo e parcial, baseado em interpretações de segunda ou terceira mão, pois apenas o nativo pode fazer uma interpretação em primeira mão, é a sua cultura. 
É possível encerrar essa exposição pensando na questão da subjetividade/objetividade na concepção dos dois autores que, me parece, os aproxima definitivamente. Em "A Ciência como Vocação" e "Metodologia das Ciências Sociais", para citar apenas dois artigos, Weber trata incansavelmente do problema da objetividade nas ciências sociais. E, acredito, ele busca uma ciência objetiva sim, mas não isenta de valores.

Já foi dito e repetido que Weber poderia ser visto como um representante do "individualismo metodológico". Sua análise parte do indivíduo, pois apenas ele é que pode atribuir sentido às ações, tornando-as sociais. Entretanto, este sentido se orienta a partir de valores ou, mais exatamente, a própria ação é orientada por valores. O sentido que importa para Weber é aquele "subjetivamente visado" e é subjetivo porque parte do sujeito. Assim, o fato social é construído subjetivamente e tem um significado subjetivo porque é construído pelo sujeito e não porque não é concreto. Cabe ao sociólogo - que também tem sua ação orientada por valores - selecionar e compreender o sentido que tenha validade universal. Aí está a validade científica.

“... apenas as idéias de valor que dominam o investigador e uma época podem determinar o objeto do estudo e os limites deste estudo. No que concerne ao método da investigação, o 'como'é o ponto de vista dominante que determina a formação dos conceitos auxiliares de que se utiliza. E quanto ao método de utilizá-los, o investigador encontra-se evidentemente ligado às normas de pensamento. Porque só é uma verdade científica aquilo que pretende ser válido para todos os que querem a verdade". (Weber: 1992, p.133)

A idéia de intersubjetividade de Geertz é muito próxima do que fala Weber. A análise de Geertz parte da ação simbólica dos indivíduo, agentes culturais cujas ações dão sentido a um emaranhado de símbolos que é a cultura. O reconhecimento deste autor de que os indivíduos es- 
tudados são capazes de interpretar e que tal interpretação interessa ao antropólogo, resulta na busca de um diálogo imediatamente difícil onde se confrontam, no melhor sentido, repertórios diferentes: o do antropólogo e o do nativo. Se uma leitura pressupõe que um campo semântico seja partilhado, como aponta Ricoeur (1988), o antropólogo pode ter o desejo de compreensão alimentado pelo conjunto de agenciamentos significativos recorrentes do sentido do outro. Um complexo jogo de interpretações e contra-interpretações, no qual apenas o nativo pode fazer uma interpretação em primeira mão, pois trata-se de sua cultura.

Neste sentido, a interpretação se constrói a partir de uma negociação de subjetividades, a chamada fusão de horizontes, o diálogo entre a subjetividade (e os valores) do antropólogo e a subjetividade (e os valores) do sujeito estudado, o qual imprime significados - públicos - à cultura investigada. Parece-me que a idéia de verdade científica de Weber está intrinsecamente vinculada ao que Geertz chama de intersubjetividade. O que Weber propõe é exatamente uma negociação de subjetividades (valores), a do pesquisador e a do pesquisado.

ABSTRACT: The aim of this paper is an effort to think about the Social action, from the point which put together and sometimes put far away the Comprehensive Sociology of Max Weber and the interpretative Anthropology of Clifford Geertz.

\section{REFERÊNCIAS BIBLIOGRÁFICAS}

AZZAN, C. Antropologia e Interpretação. Campinas: Ed. Unicamp, 1993.

CALDEIRA, T. Antropologia e Poder: uma resenha de Etnografias Americanas Recentes. Boletim Informativo e Bibliografia de Ciências Sociais, Rio de Janeiro, $\mathrm{n}^{\circ} 27,1989$. 
CARDOSO DE OLIVEIRA, R. A Categoria de (des)ordem e a pósmodernidade da Antropologia. In: Pós-Modernidade, Campinas: Ed. Unicamp, 1988.

COHN, G. (org.) Weber. São Paulo: Ática, 1991.

FREUND, J. Sociologia de Max Weber. Rio de Janeiro: Forense, 1970.

GEERTZ, C. From the Native's Point of View: on the nature of anthropological understanding. In: Local Knowledge Further Essays in Interpretative Anthrpology, New York: Basic Books, 1983.

Anti Anti-Relativismo. RBCS, São Paulo, $\mathrm{n}^{\circ} 08$, vol. 3, out/1988.

A Interpretagão das Culturas. Rio de Janeiro: Guanabara, 1989a.

El Antropologo como Autor. Barcelona: Ingraf, 1989b.

HALL, S. O interior da ciência: ideologia e a "sociologia do conhecimento". In: Da Ideologia. Rio de Janeiro: Zahar, 1980.

PEIRANO, M. O Encontro Etnográfico e o Diálogo Teórico. In: Trabalhos de Ciências Sociais. Brasilia: Série Antropológica 53, Fundação UnB, 1986.

PRATES, A. A. et al. Temas Contemporâneos de Sociologia Clássica. Belo Horizonte: UFMG/FAFICH, 1991

RICOEUR, P. Interpretasão e Ideologias. Rio de Janeiro: Francisco Alves, 1989.

ROSSI, P. Ensayos de Metodologia Sociologica - Max Weber. Buenos Aires: Amorrortu, 1973.

WEBER, M. Economia y Sociedad. México: Fondo de Cultura Económica, 1969.

A Objetividade do Conhecimento na Ciência Social e na Ciência Política - 1904. In: Metodologia das Ciências Sociais. Campinas: Ed. Unicamp, 1992.

A Ciência como Vocação. In: Ensaios de Sociologia. Rio de Janeiro: Zahar, s/d. 